\title{
Rheological Properties and Sugar Profile of a Maize-Based Complementary Food for Ugandan Children 12 to 23 Months of Age
}

\author{
Joel Tumwebaze ${ }^{1}$, Peter Gichuhi ${ }^{1}$, Vijay Rangari ${ }^{2}$, Alfred Tcherbi-Narieh ${ }^{2}$, \\ Adelia Bovell-Benjamin ${ }^{1, *}$ \\ ${ }^{1}$ Department of Food and Nutritional Sciences, Tuskegee University, Tuskegee AL, USA \\ ${ }^{2}$ Department of Materials Science and Engineering, Tuskegee University, Tuskegee AL, USA
}

\section{Email address:}

JTeomwebaze0414@mytu.tuskegee.edu (J. Tumwebaze), pgichuhi@mytu.tuskegee.edu (P. Gichuhi), rangariv@mytu.tuskegee.edu (V. Rangari), atcherbi-narteh@mytu.tuskegee.edu (A. Tcherbi-Narieh), acbenjamin@mytu.tuskegee.edu (A. Bovell-Benjamin)

\section{To cite this article:}

Joel Tumwebaze, Peter Gichuhi, Vijay Rangari, Alfred Tcherbi-Narieh, Adelia Bovell-Benjamin. Rheological Properties and Sugar Profile of a Maize-Based Complementary Food for Ugandan Children 12 to 23 Months of Age. International Journal of Nutrition and Food Sciences. Vol. 4, No. 6, 2015, pp. 631-638. doi: 10.11648/j.ijnfs.20150406.15

\begin{abstract}
In this study, the rheological properties and sugar profiles of a maize-based (maize flour, sweet potato leaf and root flour) complementary food for 12 to 23 month-old Ugandan children were evaluated. Two foods were formulated. Treatment 1 (T1) was made of 70\% maize meal, 15\% sweet potato root flour and 15\% sweet potato leaf flour, while Treatment 2 (T2) consisted of $70 \%$ maize meal, $20 \%$ sweetpotato root flour and $10 \%$ sweetpotato leaf flour. Both formulations had equal amounts of sugar, oil and added water. The viscosity of the complementary foods was determined at $45^{\circ} \mathrm{C}$ by two different methods (rheometer and line spread test). The viscosity decreased with increasing temperature for all the samples. The viscosity at $45^{\circ} \mathrm{C}$ for the Control, T1 and T2 were 1.35, 1.96 and $0.86 \mathrm{~Pa}$, respectively. There were significantly $(\mathrm{P}<0.05)$ different line spread measurements among the samples; however, the control sample flowed the greatest distance. The highest level of sugarswas found in T2 $(5.1 \pm 2.7 \mathrm{~g} / 100 \mathrm{~g})$ versus the control, which had the least amount of total sugar $(2.9 \pm 1.6 \mathrm{~g} / 100 \mathrm{~g})$. Supplementation of a maize-based complementary food with sweetpotato root and sweet potato leaf flours improves the viscosity and sugar profile.
\end{abstract}

Keywords: Viscosity, Sugar Profile, Total Sugar, Complementary Food

\section{Introduction}

Complementary foods should be added to the diets of children when breast milk is inadequate to meet their nutritional needs. The changeover from exclusive breastfeeding to family foods is referred to as complementary feeding. Complementary feeding, which usually covers the period from 6 to 24 months of age is a very vulnerable period. It is the time when malnutrition begins in many infants, contributing significantly to the high prevalence of malnutrition in children less than five years of age globally. Globally, 161 million under-five year olds were estimated to be chronically malnourished or stunted in 2013 [1]. Roughly $33 \%$ of these children reside in Africa [1].

The World Health Organization (WHO) recommends the use of local staples for complementary feeding, as these are most likely to be available, easy to prepare from family foods, and more affordable [2]. However, most staple-based complementary foods in developing countries are starchy [3-4]. Starchy foods form a highly viscous porridge on cooking and this necessitates dilution with large volumes of water for effective infant feeding [5-6]. The over-dilution, leads to a watery, reduced energy and nutrient food, which is generally referred to as nutrient thinning $[5,7]$. Nutrient thinning is one of the major causes of poor growth during the weaning period [8]. Apart from nutrient thinning, the sugar content of complementary foods also affects its rheological properties such as viscosity.

A number of studies have focused on the increase in energy density and nutritional value of complementary foods in 
developing countries [9-12]. Some studies suggest that energy value can be improved by increasing the amount of flour but, generally, an increase in flour concentration leads to production of very thick complementary foods on cooking [13-16]. Highly viscous foods are not usually acceptable to children [17]. It follows therefore that a child has to consume a lot of watery food to meet the daily nutrient requirement. However, infants' stomachs are too small (30 to $40 \mathrm{~mL}$ per $\mathrm{kg}$ ) to accommodate large volumes of food [18-19].

In developing complementary foods, strategies to improve the consistency and energy density include; i) modification of the dry matter composition by malting and fermentation [13]; ii) addition of sugar and oil [20]; iii) chemical and enzymatic starch modification; and iv) extrusion cooking [21]. To improve the energy density of complementary foods, studies that relate energy density with consistency have to be done [22]. The viscosity of complementary foods depends on factors such as, complementary food temperature, shear time, shear rate, dry matter concentration, $\mathrm{pH}$ and ionic strength, and the viscosity measurement systems [23-25].

The rheological properties of complementary foods maybe assessed using either instrumental or sensory methods. Instrumental methods involve a number of parameters whereas sensory parameters are based on visual and tactile perception prior or during consumption [25]. A line spread test that measures the distance a food/ beverage flows across a flat surface can also be used to determine the thickness of a food or beverage [26]. The line spread test is a simple test, which could be used for training caregivers to ensure that infants receive foods of the right consistency. Line spread measures are advantageous over rheometers and viscometers in that they are inexpensive and more practical, therefore they can be used at the household level [27-28].

Besides viscosity, the level of sweetness (sugar content) of complementary foods determines their acceptability and quantity consumed [29-30]. Sugars are mostly used in pastries, juices and drinks where they impart different attributes including, color (Maillard reaction), flavor, mouthfeel, leavening capacity, sweetness, stability and moisture retention [31-32]. In reference to complementary feeding, children are born with an innate preference for sweet tastes [33]. The fetus responds to sweet tastes from the amniotic fluid as early as 6 weeks and it has been shown that injection of sweet fluids increase fetal swallowing while sour fluids decrease swallowing [34-39]. At birth, most infants are fed breast milk that contains the milk sugar lactose [40-41]. The possibility exists that sweeter complementary foods will be more acceptable to children (sweeter does not always mean too much sugar that would possibly pose a health risk). Other than breast milk, studies reported that infants consumed more cereal-based porridge when sweetened [42]. Additionally, the sugar content of complementary foods has an effect on their viscosity as reported by [43]. The objective of this study was to evaluate the rheological properties and sugar profile of a maize-based (maize flour, sweet potato leaf and root flour) complementary food for 12 to 23 month-old Ugandan children.

\section{Materials and Methods}

\subsection{Flour Formulations}

Fresh Whatley/Loretan sweet potato [Ipomoea batatas (L.) Lam] roots from the George Washington Carver Agricultural Experiment Station, Tuskegee University were processed into flour. The roots were trimmed, weighed, hand washed and drained on a rack in open air for 30 minutes, as proposed by [44]. The first four leaves on a vine of Whatley/Loretan cultivar sweet potato were picked, sorted, weighed, washed and blanched. This was followed by draining, immersion in an ice bath for 10 minutes, drained again, and then dehydrated in a mechanical convection incubator (Thermo Fisher Scientific, Waltham, MA) at $65^{\circ} \mathrm{C}$ until brittle. The dried leaves were cooled, milled, weighed and stored at ${ }^{-} 14^{\circ} \mathrm{C}$ until use.

Four flour formulations were prepared from the processed sweet potato root and leaf flours, organic white maize (Zea mays) meal, oil and sugar. The maize meal was sourced from Hodgson Mill Inc. (Effingham, IL) whereas maize oil and sugar were purchased from a local grocery store. Several combinations represented in Table1were developed using Microsoft Excel 2011 predictive statistics with the intent ofselecting those that provided as close to the recommended dietary allowance of protein, energy and $\beta$-carotene for children 12 to 23 months-old [45].

Table 1. Various Prototype Combinations of the Complementary Food.

\begin{tabular}{llll}
\hline $\begin{array}{l}\text { Energy and } \\
\text { Nutrients }\end{array}$ & Control* $^{*}$ & $\begin{array}{l}\text { Treatment 1 } \\
\text { (T1) }\end{array}$ & $\begin{array}{l}\text { Treatment 2 } \\
\text { (T2) }\end{array}$ \\
\hline Energy & $463.8 \mathrm{kcal}$ & $503.0 \mathrm{kcal}$ & $502.8 \mathrm{kcal}$ \\
Protein & $18.3 \mathrm{~g}$ & $21.3 \mathrm{~g}$ & $20.2 \mathrm{~g}$ \\
Fat & $4.5 \mathrm{~g}$ & $9.9 \mathrm{~g}$ & $9.7 \mathrm{~g}$ \\
Carbohydrate & 257.9 & 249.7 & 251.1 \\
Dietary fiber & $10.0 \mathrm{~g}$ & $21.4 \mathrm{~g}$ & $19.8 \mathrm{~g}$ \\
PUFA & $0.0 \mathrm{~g}$ & $3.1 \mathrm{~g}$ & $3.1 \mathrm{~g}$ \\
Vitamin A & $5.0 \mu \mathrm{g}$ & $3.8 \mu \mathrm{g}$ & $3.8 \mu \mathrm{g}$ \\
Carotene & $0.0 \mathrm{mg}$ & $1.6 \mathrm{mg}$ & $1.8 \mathrm{mg}$ \\
Sodium & $0.0 \mathrm{mg}$ & $1.2 \mathrm{mg}$ & $1.0 \mathrm{mg}$ \\
Potassium & $718.7 \mathrm{mg}$ & $505.0 \mathrm{mg}$ & $504.8 \mathrm{mg}$ \\
Phosphorus & $525.0 \mathrm{mg}$ & $422.8 \mathrm{mg}$ & $425.8 \mathrm{mg}$ \\
Iron & $3.7 \mathrm{mg}$ & $8.9 \mathrm{mg}$ & $8.2 \mathrm{mg}$ \\
Zinc & $5.5 \mathrm{mg}$ & $4.1 \mathrm{mg}$ & $4.1 \mathrm{mg}$ \\
Total Vitamin A & $5.0 \mu \mathrm{gRAE} *$ & $137.1 \mu \mathrm{gRAE}$ & $153.8 \mu \mathrm{gRAE}$ \\
\hline
\end{tabular}

*Traditional complementary food

*RAE refers to Retinol Activity Equivalent

\subsection{Complementary Food Production}

Several cooking trials were made using the formulations treatment 1 (T1) and treatment 2 (T2) by varying water, cooking-temperature and time to come up with a complementary food of the right consistency, and flavor. For each trial, T1 and T2 were dissolved in known quantities of cold water to form a paste with no lumps, poured in a known 
quantity of boiling water and stirred continuously while cooking. The consistency was determined by cooling the porridge to approximately $45^{\circ} \mathrm{C}$ on a plate, tilting the plate to one side to observe the ease of flow.

The acceptable consistency was obtained when the food moved down slightly without running down the plate. Another test for consistency was done by pouring a small quantity of the cooled food (approximately $45^{\circ} \mathrm{C}$ ) into water at room temperature $\left(22 \pm 2^{\circ} \mathrm{C}\right)$, observing the time it took for the lump to dislodge. Once the required consistency was obtained, temperature and time were varied until standard cooking conditions were set.

\subsection{Line Spread Test for Viscosity}

A line spread test was used to objectively evaluate the viscosity based on the spreadability of the complementary foods. The viscosity of porridges; that is, the control, T1 and T2 was measured using a line spread method modified from [26]. Under this method, concentric circles of radius 2.5 to 7.5 $\mathrm{cm}$ and $0.5 \mathrm{~cm}$ apart were drawn on a hard clear plastic surface. Lines radiating from the center to intersect the circles were drawn to divide the circles into four equal quadrants at 900 intervals. For each sample, the porridge at $45^{\circ} \mathrm{C}$ was held in a hollow cylinder of height $3.5 \mathrm{~cm}$ and $5 \mathrm{~cm}$ diameter positioned at the center of the concentric circles for a setting time of 30 seconds. To ensure that equal volume of porridges were dispensed in the cylinder for each sample and replicate, the cylinders were overfilled and leveled out with a metal spatula. After 30 seconds of sitting, the cylinder was lifted off the plastic to allow the sample spread for 60 seconds. For each sample 10 measurements were done for which the mean measurement in centimeters averaged across bisecting lines at four quadrants represented the degree of thickness of each porridge.

\subsection{Instrumental Viscosity Measurement}

The viscosity for the three porridge samples was also determined in triplicate using the AR-2000 rheometer (TA Instruments, New Castle, Delaware). The porridge samples were applied to the lower plate and the rheometer calibrated to $1000 \mu \mathrm{m}$ minimum gap space. Excess porridge sample that protruded from the plates was scrapped off. To determine how viscosity changes with temperature, the rheometer was set to heat the porridge from $25^{\circ} \mathrm{C}$ to $65^{\circ} \mathrm{C}$ and values of viscosity were recorded. The change in viscosity with increasing time at a constant temperature was also measured. For this measure, the porridge at $25^{\circ} \mathrm{C}$ was heated up to $45^{\circ} \mathrm{C}$ and held for 20 minutes. The change in viscosity with time at constant temperature $\left(45^{\circ} \mathrm{C}\right)$ was recorded.

\subsection{Total Sugar Analysis}

The assay for total sugars was done using a modified Sucrose, D-Fructose and D-Glucose Assay kit with a detection limit of $1.38 \mathrm{mg} / \mathrm{L}$ and following the manufacturer's procedure (Megazyme International, Wicklow, Ireland).

\subsubsection{Sample Clarification}

Carrez 1 solution was prepared by dissolving $3.6 \mathrm{~g}$ potassium hexacyanoferrate (II) trihydrate $\{\mathrm{K} 4[\mathrm{Fe}(\mathrm{CN})$ 6].3H20 supplied by Sigma-Aldrich (Missouri, USA) in 100 $\mathrm{mL}$ of distilled water and stored in a closed glass bottle at room temperature $\left(22 \pm 3^{\circ} \mathrm{C}\right)$. Carrez II solution was made by dissolving $7.2 \mathrm{~g}$ Zinc sulfate heptahydrate (ZnSO4.7H20) in $100 \mathrm{~mL}$ distilled water and stored in a glass bottle at room temperature $\left(22 \pm 3^{\circ} \mathrm{C}\right)$. Zinc sulfate heptahydrate was supplied by Sigma-Aldrich (Missouri, USA). Sodium hydroxide $(100 \mathrm{mM})$ was prepared by dissolving $4 \mathrm{~g}$ of $\mathrm{NaOH}$ in $1 \mathrm{~L}$ distilled water and stored at room temperature $(22 \pm$ $\left.3^{\circ} \mathrm{C}\right)$.

\subsubsection{Clarification}

For each sample (control, T1 and T2), $1 \mathrm{~g}$ was weighed into each of the three $100 \mathrm{~mL}$ volumetric flask. To each volumetric flask, $60 \mathrm{~mL}$ distilled water was added and incubated at $70^{\circ} \mathrm{C}$ for 15 minutes in a water bath with occasional shaking after every five minutes. To clarify the samples, $5 \mathrm{~mL}$ Carrez 1 solution, $5 \mathrm{~mL}$ of Carrez II and $10 \mathrm{~mL} \mathrm{NaOH}$ prepared in step 1 , were added to each volumetric flask and mixed after addition of solution. The contents of the volumetric flask were cooled to room temperature $\left(22 \pm 2^{\circ} \mathrm{C}\right)$ after which distilled water was added to the mark. The volumetric flasks were sealed with parafilm to enable thorough mixing. The clarified samples were vacuum filtered using a Buchner funnel and Whatman filter paper no.2. (Sigma Aldrich, Missouri, USA) to obtain a clear filtrate for the assay. All samples including the control, T1 and T2 were prepared in triplicate.

\subsubsection{Total Sugar Assay}

For each sample (control, T1 and T2) four plastic cuvettes of $1 \mathrm{~cm}$ light path were set in order of; blank sucrose sample, Sucrose sample, Blank D-glucose/ D-fructose sample and D-glucose/D-fructose sample. All reagents in the assay were part of the Sucrose, D-Fructose and D-Glucose Assay kit supplied by Megazyme International (Wicklow, Ireland). Absorbance was read at $340 \mathrm{~nm}$ using a Shimadzu UV-1201 UV-VIS Spectrophotometer (Shimadzu, Kyoto, Japan).

Step 1: $\beta$-fructosidase $(0.2 \mathrm{~mL})$ was pipetted into the blank sucrose sample and sucrose sample cuvettes. To the sucrose sample and D-glucose/D-fructose sample cuvettes, $0.1 \mathrm{~mL}$ sample solution was pipetted, vortexed for 1 minute and thereafter incubated for 5 minutes. After 5 minutes, 2, 1.9, 2.2 and $2.1 \mathrm{~mL}$ distilled water were added to the blank sucrose, D-glucose/ D-fructose, and D-glucose/D-fructose samples, respectively. To each of the four cuvettes $0.1 \mathrm{~mL}$ buffer solution and $0.1 \mathrm{~mL}$ NADP+/ATP were added, vortexed for 30 seconds and after 3 minutes of incubation, the absorbance (A1) was read and recorded.

Step 2: Hexokinase/glucose-6-phosphate dehydrogenase $(0.02 \mathrm{~mL})$ was pipetted into each of the four cuvettes, vortexed for 30 seconds and the absorbance (A2) read after 5 minutes of incubation.

Step 3: Phosphoglucose isomerase $(0.02 \mathrm{~mL})$ was pipetted into the blank and sample cuvettes D-glucose/ D-fructose and vortexed for 30 seconds. The absorbance (A3) was read after 
incubation for 10 minutes. All sample analysis was done in triplicate.

Calculation of total sugars: The concentration of total sugars were calculated from the absorbance differences (A2-A1) and (A3-A1) for both blanks and samples. From the absorbance differences, the changes in absorbance due to D-glucose, D-fructose and Sucrose were obtained and used to calculate the concentration of D-glucose, sucrose and D-fructose.

\subsection{Statistical Analysis}

Data for rheological measures was analyzed using Analysis of Variance (ANOVA) to compare: i) how viscosity changes with time among the control, T1 and T2; (ii) the viscosity at $45^{\circ} \mathrm{C}$ for the three formulations; and (iii) how viscosity changes at a $45^{\circ} \mathrm{C}$ with change in time for the three formulations. Pearson's correlation was used to determine the relationship between the viscosity at $45^{\circ} \mathrm{C}$ of the line spread test and the rheometer. Fisher's LSD was used to determine where the differences exist using a 95\% confidence interval.

\section{Results}

\subsection{Line Spread Measures}

Line spread measurements showed that the control food flowed the greatest distance followed by T1 then T2 (Figure 1). Results showed significantly $(\mathrm{P}<0.05)$ different line spread measurements among the samples.

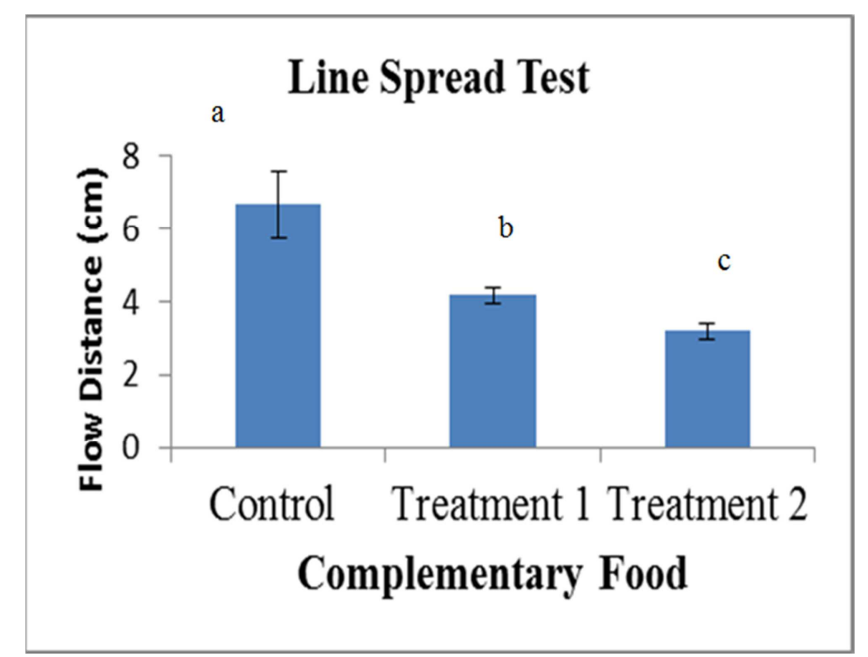

Figure 1. Line Spread Test for the Maize-based Complementary Food.

\subsection{Viscosity and Temperature}

Viscosity measures were determined on heating the porridges from $30^{\circ} \mathrm{C}$ to $65^{\circ} \mathrm{C}$. The viscosity decreased with increasing temperature for all the samples as shown in Figure 2. However at all temperatures, the viscosity of $\mathrm{T} 1$ remained higher than the other two samples. The viscosity at $45^{\circ} \mathrm{C}$ for the Control, $\mathrm{T} 1$ and $\mathrm{T} 2$ were $1.35,1.96$ and 0.86 pascals per second [Pa.s], respectively.

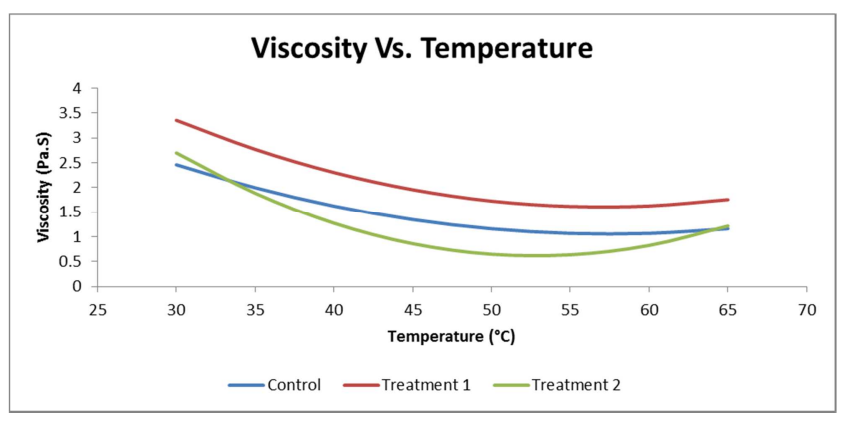

Figure 2. Flow Curve for the Maize-based Complementary Food.

\subsection{Viscosity, Temperature and Time}

Changes in viscosity after holding the porridge samples at $45^{\circ} \mathrm{C}$ for 20 minutes were determined. This part of the study mimicked the changes in viscosity on storage of the porridge in a thermos for later use. Generally, the viscosity decreased slightly with increased time for all the three porridge samples from 11 to 20 minutes of holding (Figure 3 ). The point decline in viscosity was highest in $\mathrm{T} 2$, followed by $\mathrm{T} 1$ and the Control with values of $1.2,0.85$ and 0.4 pascals-second, respectively.

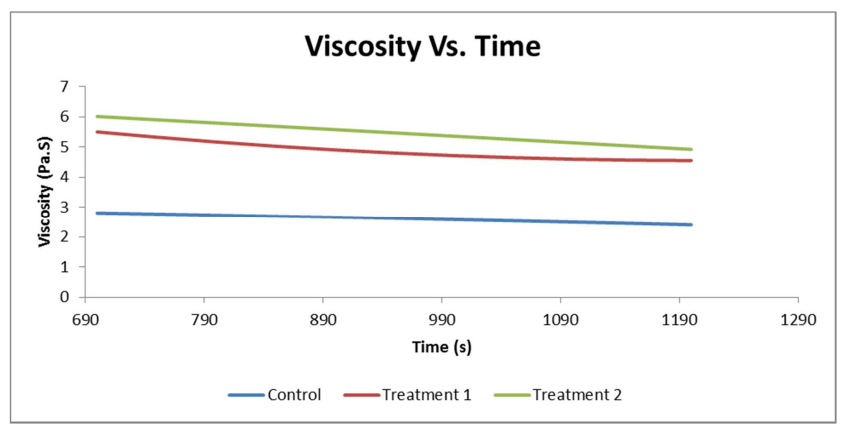

Figure 3. Flow Curve for the Maize-based Complementary Food.

\subsection{Line Spread and Rheometer Relationship}

The correlation coefficient for viscosity measurements at $45^{\circ} \mathrm{C}$ between the line spread and rheometerwas significantly different $(\mathrm{P} \leq 0.05)$ for the three samples. Based on the results, there was a strong relationship between the line spread test and the rheometer measurement $(\mathrm{r}=0.8)$ for the control sample, meaning both tests yielded similar results. Treatment 1 showed a moderate, positive correlation $(r=0.4)$ between the measurement methods. Treatment 2 displayed a very weak positive correlation $(\mathrm{r}=0.1)$ between the line spread and rheometer.

\subsection{Sugar Profile}

According to the findings, the total sugar content was significantly different $(\mathrm{P} \leq 0.05)$ for each sample (Table 2$)$. The highest level of sugars (g/100 g sample?) was found in $\mathrm{T} 2$ $(5.1 \pm 2.7)$ versus the control, which had the least amount of total

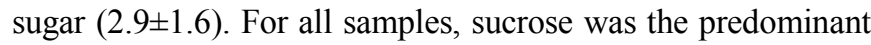
sugar, while fructose was absent in the control (Table 2). According to our results $\mathrm{T} 2$ had significantly $(\mathrm{P} \leq 0.05)$ higher amounts of glucose and fructose than the control and T1. The control and T1 had equal amounts of glucose. 
Table 2. D-Glucose, Sucrose and D-Fructose Contents of Complementary Foods.

\begin{tabular}{lllll}
\hline \multicolumn{5}{l}{ Sugar Concentration (g/100 g sample) } \\
\hline Sample & D-Glucose & Sucrose & D-Fructose & Total Sugars \\
\hline Control & $0.1 \pm 0.03 \mathrm{a}$ & $2.8 \pm 0.1 \mathrm{a}$ & $0.0 \pm 0.0 \mathrm{a}$ & $2.9 \pm 1.6 \mathrm{a}$ \\
Treatment1 & $0.1 \pm 0.03 \mathrm{a}$ & $4.2 \pm 0.3 \mathrm{~b}$ & $0.1 \pm 0.02 \mathrm{~b}$ & $4.4 \pm 2.4 \mathrm{~b}$ \\
Treatment2 & $0.2 \pm 0.1 \mathrm{~b}$ & $4.8 \pm 0.3 \mathrm{~b}$ & $0.2 \pm 0.04 \mathrm{c}$ & $5.1 \pm 2.7 \mathrm{c}$ \\
\hline
\end{tabular}

Numbers in each column with the same letters are not significantly different from each other

\section{Discussion}

\subsection{Line Spread Measures}

Lower line spread values reflect more viscous products whereas higher mean values reflect less viscous products. Based on the results of the current study, at $45^{\circ} \mathrm{C}$, the control and Treatment 1 samples had viscosities within the range recommended for infant and young child feeding ( 1 to 3 Pascal-Second) [17]. The viscosity at $45^{\circ} \mathrm{C}$ was of interest because it is the temperature at which viscosity measurements for complementary foods are taken [46].

Studies show that complementary foods prepared from cereals alone always have a high viscosity unless modified by substitution with less starchy foods, extrusion, fermentation or enzymatic action $[5,7,47]$. Orange-fleshed sweet potato flour and maize flour have approximately the same starch content, starch particle size and amylose content [48-50]. However, according to $[5,51]$, sweet potato-based formulations have lower starch content and higher sugar content, and therefore a lower apparent viscosity at $45^{\circ} \mathrm{C}$.

In the current study, Treatments 1 and 2 had sweetpotato root flour and higher sugar concentrations. The presence of more total sugars in Treatments 1 and 2 could have been responsible for the lower viscosities observed. Treatment 2 had more sugar and less starch than any of the other samples, which could be responsible for its very poor viscosity at $45^{\circ} \mathrm{C}$. The effect of sugar on thermal and physical properties of starch-based foods was studied by other researchers $[43,52]$. Having more water in the control when compared to Treatment 1 may have interfered with the formation of a thick gel when the starchy food was heated, hence a reduced viscosity [16]. Consequently, having less water than the Control, the viscosity of $\mathrm{T} 1$ was within the range recommended for complementary feeding $(1$ to 3 Pascal-Second)[17].

\subsection{Viscosity, Time, Shear Rate and Temperature}

Changes in viscosity after holding the porridge samples at $45^{\circ} \mathrm{C}$ for 20 minutes were determined. This part of the study mimics the changes in viscosity on storage of the porridge in a thermos flask for later use. However, data on holding the samples from 0 to 10 minutes was excluded in the analysis because of temperature fluctuations within the system. Generally, for all the samples, viscosity decreased slightly with increase in time (between 11 and 20 minutes of holding). It is speculated that the decline in viscosity with time at constant temperature and shear rate, that is thixotropy, was due to the progressive breakdown of forces holding suspended particles under a given shear stress, resulting in reduction in particle size of structural particles, which offer lower resistance to flow during shear [53].

As the number of disrupted inter-particle bonds increases, the viscosity drops [24]. After some time the number of breakdown of particles is similar to aggregation and a straight curve is obtained [54]. At low concentration of the sample, thixotropy is almost non-existent as in the case of the control, which was more diluted with water compared to T1 and T2. Thixotropic behavior is exhibited more at higher temperatures of holding [55]. Our findings are consistent with those reported by Abu-Jdayil[55] as both studies were held at $45^{\circ} \mathrm{C}$.

\subsection{Line Spread and Rheometer Measures}

The relationship between the line spread and rheometer measure at $45^{\circ} \mathrm{C}$ was assessed for its significance as well as its strength. The correlation coefficient for viscosity measurements at $45^{\circ} \mathrm{C}$ was significant $(\mathrm{P} \leq 0.05)$ for the three samples. This could imply that the line spread test could be used to test the consistency of complementary foods at a similar level of accuracy as one using a rheometer. As a rheometer is more expensive and requires highly technical skills for operation, a line spread test would be a better alternative for training caregivers in developing countries.

\subsection{Sugar Content Analysis}

During the formulation of the complementary mixes, all samples had $12 \mathrm{~g}$ sucrose added therefore the difference in sugar concentration after analysis is attributed to endogenous sugars. Since the concentration of sucrose varied considerably among samples, it was assumed that sucrose contributed largely to the total sugars of the samples. Results from this study are consistent with those reported by other researchers [56]. According to these authors, sucrose was the major sugar in six sweetpotato cultivars. The control had only maize meal whereas Treatments 1 and 2 had sweetpotato leaf and root flour in addition to maize meal. This could imply that maize meal formulation had less endogenous sugars than the other two ingredients.

The low sugar content in the control could also be due to the additional water that was added to bring the viscosity to within the recommended range for complementary feeding. The difference in sugar content between Treatment 1 and 2 could be due to the difference in quantity of sweetpotato root flour. T2 had 25\% more sweetpotato root flour than T1. Orange-fleshed sweet potato root flour has been reported to contain endogenous sugars that improved the sweetness of complementary foods [5]. Sweet potato roots were found to have a total sugar content ranging between 2.2 and $2.8 \mathrm{~g} / 100 \mathrm{~g}$ [57]. Studies show that foods with more sugar were more accepted for complementary feeding $[29,58]$. Children are born with an innate preference for sweet taste; sweetness is an important determinant of food preferences [33]. It is therefore highly likely that children will prefer sweeter complementary 
foods. However, complementary foods with higher sugar contents are more likely to be less the viscosity [43]. Although T2 had the highest amount of sugar, its viscosity was unacceptable for complementary feeding [17]. However, it was noted that the level of sweetness after cooking of carbohydrate foods was not determined by the level of sucrose but by the enzymatic conversion of starch to maltose [59-60]. Contradictory to the previous statement, [61] reported that the sugar composition of a cultivar, especially the sucrose values gives a reliable indication of its sweetness. It is therefore recommended that tests of acceptability should be carried out along with total sugar analysis tests for complementary foods supplemented with sweet potato root flour.

\section{Conclusion}

Using the line spread test, the viscosity at $45^{\circ} \mathrm{C}$ increased from the control, Treatment 1 to Treatment 2. Rheometric determinations however showed that at $45^{\circ} \mathrm{C}$, Treatment 1 had the highest viscosity and the least was recorded in Treatment 2. The viscosity at $45^{\circ} \mathrm{C}$ also showed that Treatment 1 and the control had viscosities within the range recommended for complementary feeding. Viscosities for all the three formulations decreased when temperatures were increased from 30 to $65^{\circ} \mathrm{C}$. Pearson's correlation showed that the rheometric and line spread test viscosity determinations were highly correlated for the control and Treatment 1. The correlation coefficient declined as the viscosity decreased implying that the line spread test may not be a useful tool for highly viscous foods. The line spread test could be a practical, feasible option for training caregivers in developing countries to measure the viscosity of complementary foods, especially because the rheometer is quite expensive and requires highly technical skills for operation.

\section{Acknowledgements}

The authors would like to thank Dr. Eunice Bonsi for procuring the financial support for the research. The United States Agency for International Development's Feed the Future Nutrition Innovation Lab-Africa/Tuft University/Tuskegee University for the financial support to conduct this research under USAID grant number AID-OAA-L10-00006.

\section{References}

[1] Krasevec, J. Thompson, A., Blössner, M. Borghi, E., Feng, J., Serajuddin, U. Overview UNICEF-WHO-The World Bank Joint Child Malnutrition Estimates 2014. (2014). (http://www.who.int/entity/nutgrowthdb/jme_unicef_who_wb. pdf).

[2] World Health Organization (WHO). Complementary feeding: Family foods for breastfed children, Geneva, World Health Organization (2000): (WHO/NHD/00.1).

[3] Kikafunda, JK, Walker, AF, Tumwine, JK. Weaning foods and practices in Central Uganda: A cross-sectional study. AJFAND (2003); 3(2)Electronic article; http://www.ajfand.net.

[4] Gibson, RS, Hotz, C. The adequacy of micronutrients in complementary foods. Pediatrics. (2000) 106 (5): 1289-1299.

[5] Amagloh, FK, Mutukumira, AN, Brough, L., Weber, JL, Hardacre, A., Coad, J. Carbohydrate composition, viscosity, solubility, and sensory acceptance of sweetpotato- and maize-based complementary foods. Food Nutr Res (2013): 57:18717 doi:10.3402/fnr.v57i0.18717.

[6] Svanberg U. Dietary bulk in weaning foods and its effect on food and energy intake. In: Alnwick D, Mose S. Schimdt OG, eds. Improving young child feeding in eastern and southern Africa: household-level food technology. Ottawa, Canada: IDRC (1988): 272-87.

[7] Temesgen M. Nutritional Status of Ethiopian Weaning and Complementary Foods: A Review. Scientificreports. 2013; 2:621.

[8] Ljungqvist, B., Mellender, O., Svanberg, U. Dietary bulk as a limiting factor for nutrient intake in preschool children: A problem description. J Trop Pediatr (1981): 27: 6873.

[9] Adenuga, W. Nutritional and sensory profiles of sweet potato-based infant weaning food fortified with cow-pea and peanut. J. Food Tech. (2010) 8(5): 223-238.

[10] Nagai, T., Staatz, JM, Bernsten, RH, Sakyi-Dawson, EO, Annor, GA. Locally processed roasted-maize-based weaning foods fortified with legumes: Factors affecting their availability and competitiveness in Accra, Ghana. AJFAND (2009) 9(9): 1945-1965.

[11] Lin, AC, Manary, JM, Maleta, K., Briend, A., Ashorn, P. An energy dense complementary food is associated with modest increase in weight gain when compared with a fortified porridge in Malawian children aged 6-18 months. J. Nutr (2008) 138(3): 593-598.

[12] Abebe, Y., Stoecker, JB, Hinds, JM, Gates, EG. Nutritive value and sensory acceptability of corn and Kocho-based foods supplemented with legumes for infant feeding in southern Ethiopia. AJFAND (2006) 6(1): 1-19.

[13] Gernah, ID, Ariahu, CC, Umeh, UE. Physical and microbilogical evaluation of food formulations from malted and fermented maize (Zea mays L.) fortified with defatted sesame (Sesamumindicum L.) flour. AJFST (2012) 4(3): $148-154$.

[14] Mburu, WM, Gikonyo, KN, Kenji, MG, Mwasaru, MA. Properties of complementary food based on amaranth grain (Amaranthuscruentus) grown in Kenya. J. Agric. Food. Tech(2011) 1(9): 153-178.

[15] Tizazu, S., Urga, K., Abuye, C., Retta, N. Improvement of energy and nutrient density of sorghum-based complementary foods using germination. AJFAND (2010) 10(8): 2927-2942.

[16] Black, TC, Pahulu, FH, Dunn, LM. Effect of preparation method on viscosity and energy density of fortified humanitarian food-aid commodities.Int J Food SciNutr (2009) 60 (Suppl 7): 219-28.

[17] Oyarekua, MA. Evaluation of the nutritional and microbiological status of co-fermented cereals/cowpea 'OGI'. Agric Biol J N Am (2011) 2(1): 61-73. 
[18] Dewey, KG. The challenge of meeting nutrient needs of infants and young children during the period of complementary feeding: An evolutionary perspective. J Nutr (2013) 143: 2050-2054.

[19] Monte, GMC, Giugliani, JRE. Recommendations for the complementary feeding of the breastfed child. J Pediatr (Rio J)(2004) 80 (5 Suppl): S131-S141.

[20] De Pee S, Bloem WM. Current and potential role of specially formulated foods and food supplements for preventing malnutrition among 6 to 23 month-old children and for treating moderate malnutrition among 6 to 59 month-old children. The United Nations University. Food Nutr Bull. (2009) 30(3Suppl): 254-259.

[21] Hoan NV, Mouquet-River C, Eymard-Duvernay S, Treche S. Effects of extrusion cooking and amylase addition to gruels to increase energy density and nutrient intakes by Vietnamese infants. Asia Pac J ClinNutr (2010) 19(3): 308-315.

[22] Kikafunda JK, Walker AF, Abeyasekera, Savitri.Optimising viscosity and energy density of maize porridges for child weaning in developing countries. Int J Food SciNutr (1997) 48 (6): 401-409.

[23] Wang Q, Cui WS. Understanding the physical properties of food polysaccharides. Taylor \& Francis Group, New York (2005).

[24] Mouquet C, Treche S. Viscosity of gruels for infants: a comparison of measurement procedures. Int J Food SciNutr (2001) 52: 398-400.

[25] Mouquet C. Consistency of gruels for infants: A comparison of measurement procedures and the main influencing factors. International Conference of Ibadan (1998): 16-21 November 1998.

[26] Budke J, Garcia JM, Chambers E 4th. Comparison of thickened beverages using line spread measurements. J Am Diet Assoc (2008) 108 (9): 1532-5.

[27] Mann LL, Wong K. Development of an objective method for assessing viscosity of formulated foods and beverages for the dysphagic diet. J Am Diet Assoc (1994) 96: 585-588.

[28] Smith TL, Sun MM, Pippin J. Characterizing process control of fluid viscosities in nursing homes. J Am Diet Assoc. (2004) 104 (6): 969-971.

[29] Muhimbula HS, Issa-Zacharia A, Kinabo J. Formulation and sensory evaluation of complementary foods from local, cheao and readily available cereals and legumes in iringa, Tanzania. Afr. J. Food Sci. (2011) 5 (1): 26-31.

[30] Paul KH, Dickin KL, Ali NS, Monterrosa EV, Stoltzfus RJ. Soy and rice-based processed complementary food increases nutrient intakes in infants and is equally acceptable with or without added milk powder. J. Nutr. (2008) 138: 1963-1968.

[31] Suas, M. Advanced Bread and Pastry: A Professional Approach. $1^{\text {st }}$ ed. Cengage Learning, 2008. 784-85.

[32] Ashurst PR. Chemistry and technology of soft drinks and fruit juices. $2^{\text {nd }}$ edn. UK John Wiley and sons, 2008.

[33] Stephen A, Alles M, de Graaf C, Fleith M et al. The role and requirements of digestible dietary carbohydrates in infants and toddlers. Eur J ClinNutr. (2012) 66: 765-779.

[34] Tassone SA, Landherr KM. Spiritual pregnancy: Develop, nurture and embrace the journey to motherhood. Woodbury. Llewellyn Worldwide, 2014.

[35] Blackburn ST. Maternal, fetal and Neonatal physiology: A clinical perspective. Fourth edition. Missouri. Elservier health sciences, 2012.

[36] Goudoever HV, Guandalini S, Kleinman RE. Early nutrition: Impact on short-and long-term health. Kaeger medical and scientific publishers, Switzerland. 2011.

[37] Newman B, Newman P. Development through life: A Psychosocial approach.Wadsworth. newyork, 11 th edition. Cengage learning, 2011.

[38] Levine LE, Munsch J. Child development: An active learning approach. Sage Publications, Inc. Thousand Island, California (2010).

[39] Ridgway R, House SH. The unborn child: Beginning a whole life and overcoming problems of early origin. H. Karnac (Books) Ltd London. 2006

[40] Lawrence RA, Lawrence RM. Breastfeeding: A guide for the medical profession. $7^{\text {th }}$ edition. Missouri, Elservier Health Sciences, 2011

[41] Coad J, Dunstall M. Anatomy and physiology for midwives, $3^{\text {rd }}$ edition. Elsevier Health Sciences, Missouri (2011).

[42] Vieu MC, Traore T, Treche S. Effects of energy density and sweetness of gruels on Burkinabe infant energy intakes in free living conditions. Int J Food SciNutr (2001) 52: 213-8.

[43] Pongsawatmanit R, Temsiripong T, Suwonsichon T. Thermal and rheological properties of tapioca starch and xyloglucan mixtures in the presence of sucrose. Food Res. Int(2007) 40:239-248.

[44] Berchoff A, Westby A, Owori C, et al. Effect of drying and storage on the degradation of total carotenoids in orange-fleshed sweet potato cultivars. J Sci Food Agric (2010) 90:622-629.

[45] Dewey KG, Brown KH. Update on technical issues concerning complementary feeding of young children in developing countries and implications for intervention programs. Food Nutr Bull (2002) 24 (1): 5-28.

[46] Treche S, MbomeLape I. Viscosity, energy density and osmolality of gruels for infants prepared from locally produced commercial flours in some developing countries. Int. J. Food Sci. Nutr. (1999) 50: 117-125.

[47] Saalia FK, Ankamah S, Otubuah B, Barfi NK, Tano-Debrah K. Development and characterization of low viscosity porridge (koko) flour by co-fermenting with millet malt. Scientific Reports (2012) 1 (12): 1-7.

[48] Adejumo LA, Aderibigbe AF, Owolabi UR. Relationship between amylase degradation and amylase/ amylopectin content of maize starches. Adv. Appl. Sci. Res. (2013) 4(2): 315-319.

[49] Nabubuya A, Namutebi A, Byaruhanga Y, Narvhus J, Wicklund T. potential use of selected sweetpotato (Ipomeabatatas (L.) Lam) varieties as defined by chemical and flour pasting characteristics. Food NutrSci (2012) 3: 889-896.

[50] Nada T, Takahata Y, Sato T, Ikoma H, Mochidas H. Physiochemical properties of starches from purple and orange fleshed sweetpotato roots at two levels of fertilizer. Starch/Starke (1996) 48 (11-12): 395-399. 
[51] Sharma A, Chen CR, Vu Lan N. Solar energy drying systems: A review. Renew SustEnerg Rev. (2009) 13:1185-1210.

[52] Kruger A, Ferrero C, Zaritzky NE. Modelling corn starch swelling in batch systems: effect of sucrose and hydrocolloids. J. Food Eng (2003) 58: 125-133.

[53] Arana I. Physical properties of foods: Novel measurement techniques and applications. Bica Raton, FL, USA, 2012.

[54] Smith GP. Introduction to food process engineering. New York NY: Springer; 2011

[55] Abu-Jdayil B. Modelling the time-dependent rheological behavior of semisolid foodstuffs. J. Food Eng. (2003) 57 (1): 97-102.

[56] La Bonte DR, Picha DH. Carbohydrate-related changes in sweetpotato storage roots during development. J. Amer. Soc. Hort. Sci. (2000) 125 (2): 200-204.
[57] Mitra S. Nutritional status of orange-fleshed sweetpotatoes in alleviating vitamin A malnutrition through a food-based approach. J Nutr Food Sci (2012) 2: 160

[58] Paul KH, Dickin KL, Ali NS, Monterrosa EV, Stoltzfus RJ. Soy and rice-based processed complementary food increases nutrient intakes in infants and is equally acceptable with or without added milk powder. J. Nutr. (2008) 138: 1963-1968.

[59] Kays SJ, Wang Y, McLaurin. Chemical and geographical assessment of the sweetness of the cultivated sweet potato clones of the world. J AmerSocHort Sci. (2005) 130 (4): 591-591.

[60] International Potato Centre (CIP). Exploration, maintenance, and utilization of sweet potato genetic resources: Report of the First Sweet potato Planning Conference (1988). Lima, Peru.

[61] Lebot V. Tropical root and tuber crops: Cassava, sweet potato, yams and aroids. CABI Publishers, Oxfordshire UK (2009). 